\title{
Risk Assessment of Rockfall Hazards in a Tunnel Portal Section Based on Normal Cloud Model
}

\author{
Xin-tong Wang, Shu-cai Li, Xiu-yuan Ma, Yi-guo Xue*, Jie Hu, Zhi-qiang Li \\ Geotechnical and Structural Engineering Research Center, Shandong University, \\ Jinan 250061, Shandong, China
}

Received: 5 October 2016

Accepted: 11 January 2017

\begin{abstract}
In mountainous regions, rockfall is a typical geological disaster which might bring immense casualties and economic losses, but also endanger the safety of civil engineering construction. Many tunnels are being built in the southwest of China, thus a comprehensive assessment for rockfall risk is needed. For this purpose, in this paper, based on normal cloud model theory, we created a multi-index evaluation model for the rockfall risk assessment. Then, according to previous research and specific geological conditions, potential tunnel dangers are classified into four ranks, and some geological factors are considered as the principal factors. In order to fully express the opinions of experts, the qualitative indices were quantified by continuous value scale. Moreover, the value of each index is determined by expert scoring. In view of different evaluation units, we used the normalization method to make geological indices dimensionless. And three numerical characteristics $(E x, E n$, and $H e$ ) were calculated by the cloud generator algorithm with MATLAB. In this study, we assigned the weight of indices by simple dependent function to avoid the influence of subjective. Finally, by means of a normal cloud generator, we determined the integrated certainty grades. To ensure the accuracy of the normal cloud model method, it was tested in rockfall cases in Jiefangcun tunnel. And the results obtained by the cloud model method are in good agreement with the practical situation. Moreover, the results are better than those of the AHP-FUZZY and artificial neural networks methods after comparison. The cloud model-based method realizes a multi-criteria assessment of the rockfall risk in tunnel portal section and provides a practical guide on safe tunnel construction for similar projects.
\end{abstract}

Keywords: rockfall, normal cloud model, risk assessment, tunnel entrance

\section{Introduction}

In recent years, increasing casualties and economic losses as a result of unexpected extreme environmental conditions have been noticed $[1,2]$, and rockfall is one of

*e-mail: xygxieagle@163.com the most serious geological hazards in mountain valleys, tunnels, and highways [3, 4]. Rockfall is a common type of rapidly moving landslide that greatly endangers the safety of tunnel construction [5-7]. In southwestern China, many tunnels have been built under limited geological conditions. Moreover, rockfall is the most common cause of landslide catastrophes in mountain areas of Sichuan Province [8]. Therefore, it is crucial to predict the 
occurrence probability of rockfall to ensure the safety of tunnel construction and normal operation of railways in southwestern China.

For trouble in quantifying the vulnerability, the lack of collected data, and the nature of rocks in a specific site [9-10], a lot of research has been carried out regarding rockfall risk in recent years. Specifically, in view of the influencing factors of rockfall hazards varying by project, a large number of outdoor experiments for rockfall have been carried out to test the main factors, for example the effects of rockfall volume [11], the size and shape of rockfall, fall paths, and trajectories [12-14]. Additionally, some other research has also assessed the risk of rockfall by using terrestrial lasers [1], GIS ${ }^{3 \mathrm{D}}$ software [5], and remote sensing spatial-temporal analysis [3].

In the past few decades, related studies have been carried out in various fields, such as mines, highways, road rock cut slopes, and scenic spots $[3,5,9,10,15]$, proposing a great deal of methods and methodologies, for instance the analytic hierarchy process (AHP), the neural network (NN), the fuzzy mathematics theory (FMT), and so on [16-19]. And an overview of qualitative rockfall hazard assessment used in underground rock engineering was provided [20].

However, only several methods have been applied to assess the risk of rockfall in the slope of tunnels and highways. According to Russell, the Rockfall Hazard Rating System (RHRS) was created by adding geological and climatic factors [21]. Wang [22] found a quantitative rockfall risk assessment (QRA) applied to a slope and adopted a first-order second moment (FOSM) for an explicit assessment of uncertainty. Based on extensive field studies and the lumped-mass method, the stability assessment of the rockfall has been presented in Gökgöl tunnel by means of numerical analyses [23]. Ye [24] provided a new evaluation method for the hazard grading of the rockfall at the slope segment of the tunnel entrance. Gao [17] raised an intelligence method for rockfall risk assessment based on a rough set and neural network to reduce the complexity and improve accuracy.

But the above-mentioned methods have their limitations. Most studies assign the weight of indices failing to avoid the influence of subjective and ignoring geotechnical uncertainty. Moreover, most studies cannot take multi factors into account. They evaluate the risk of rockfall by combining consequences and probability of the rockfall collapsing, but do not consider the reliability of evaluation results. Hence, there is a need to propose a multi-index comprehensively evaluation system in tunnels to assess the risk of rockfall by using normal cloud model theory.

\section{Study Area}

Chenglan railway is located in China's Sichuan and Gansu provinces, which has 33 newly constructed tunnels. The total length of all tunnels in this railway is $472.819 \mathrm{~km}$, and there are 13 tunnels whose length is more than $10 \mathrm{~km}$. Moreover, the geological conditions are extremely complex, and a great number of disasters, such as landslides, earthquakes and flooding, often occur during tunnel construction.

The Jiefangcun tunnel is situated in Songpan county, about $200 \mathrm{~km}$ north of Chengdu, the capital of Sichuan Province (Fig. 1). The Jiefangcun tunnel is $3.8 \mathrm{~km} \mathrm{long,}$ making it one of the longest railway tunnels between Chengdu and Lanzhou. The buried depth of the tunnel ranges from $52 \mathrm{~m}$ to $601 \mathrm{~m}$. The main geological formations crossed by the tunnel are limestone, sandstone, phyllite,

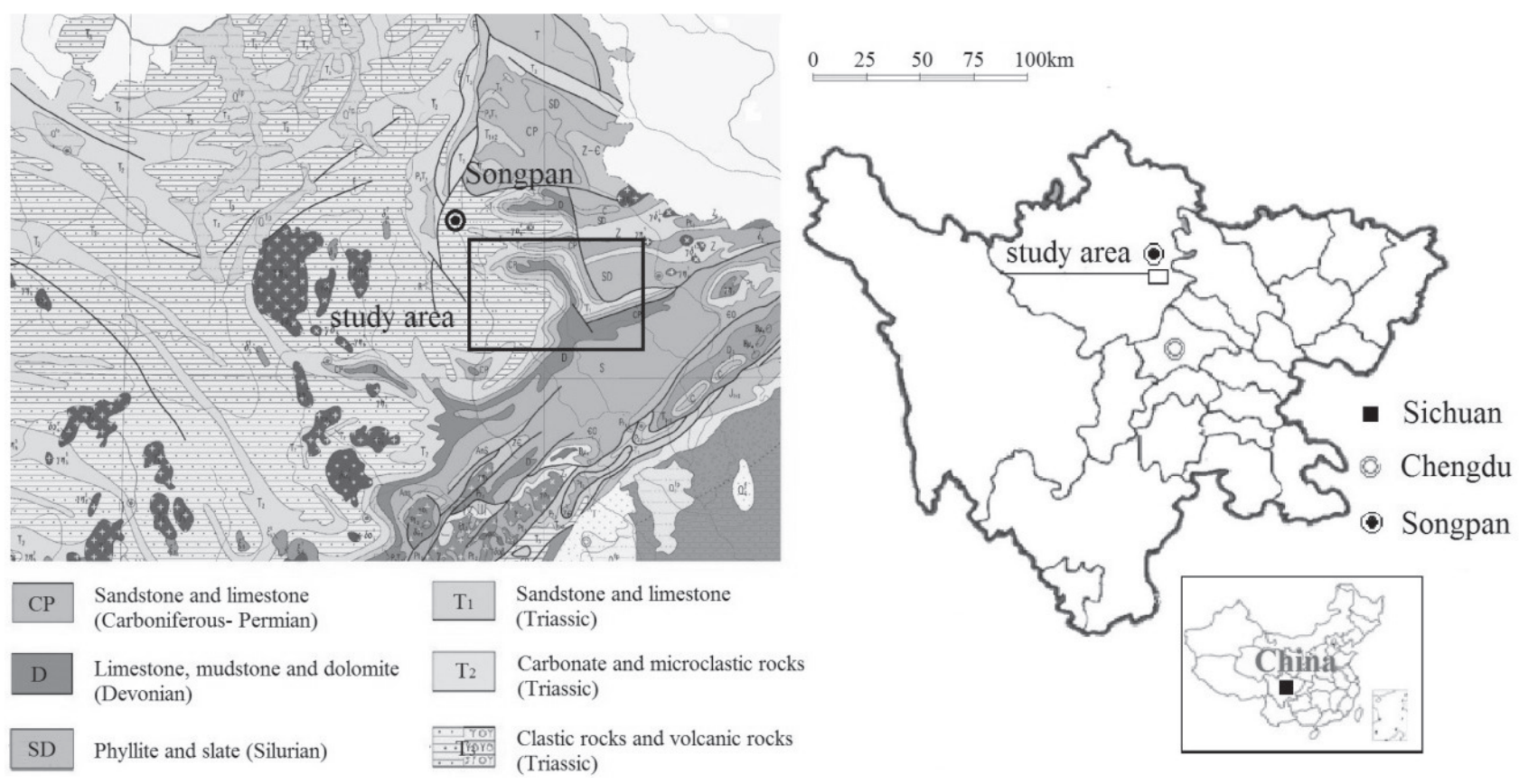

Fig. 1. Study area and geological condition of Songpan, Sichuan. 
and mudstone. The study area lies within the eastern edge of the Tibetan Plateau, where terrain is incised intensely, and hills near the study area range from 2,370 $\mathrm{m}$ to 3,026 $\mathrm{m}$ in elevation. Moreover, intense erosion and weathering processes along the mountains have created a cliffy topography where the gradient ranges from $30^{\circ}$ to $85^{\circ}$. In addition, the toe of high-steep slope above the tunnel portal section is encircled by National Highway No. G213. In order to ensure the safety of tunnel construction and reduce casualties and economic losses, the normal cloud model method has been applied to Jiefangcun tunnel. A brief risk assessment of rockfall hazards in the tunnel portal section is included in this paper.

\section{Methodology}

The concepts of rockfall hazard have various uncertainties, such as randomness and fuzziness. For example, the time rock will slide or fall and spatial distribution of rockfall are random, and the fuzzy bounds of affecting factors of rockfall hazard are difficult to be precisely defined. Thus, it is essential to introduce the cloud model to discuss the randomness and fuzziness of rockfall hazard. Cloud model theory was proposed in 1995 by Professor Li based on the study of probability and fuzzy sets theory [25-27]. Probability theory used normal distribution as an approximation to deal with random uncertainty, and the fuzzy sets theory uses normal membership function to reveal many fuzzy concepts. Cloud models can describe the inherent relationship between randomness and fuzziness and implement transformation between qualitative concept and quantitative characteristics. At present, cloud models have been researched in-depth and successfully applied to a lot of fields, for example simulation, evaluation, geological forecast, image processing, and other areas [28-30].

\section{The Basic Definition of Cloud Model}

The cloud model is a new graphic model that pictures the randomness and fuzziness of a concept to make it more concise and clear through comprehensive analysis [31]. Some quantitative numbers are adopted to represent qualitative concepts, and the cloud generator makes the uncertainly conversion between numbers and concepts much easier, as a powerful means of the cloud model.

Specifically, the definition is that $X$ is the universe of discourse and $Y$ is a qualitative concept connected with $X$. If the quantitative number $x$ belongs to $X$ and $x$ is a random instantiation of concept $Y$, the certainty grade $\mu(x)$ for $x$ belonging to $Y$ is a random variable with a stable trend. The parameter $\mu(x)$ can be estimated as:

$$
\mu: X \rightarrow[0,1] \quad \forall x \in X \rightarrow \mu(x)
$$

The distribution of $x$ is defined as cloud and each $\mathrm{x}$ is called cloud drop. The cloud drop is a tool as a quantitative meaning to describe a qualitative concept. Moreover, the production process of cloud drops represents the uncertainty of conversion between qualitative concept and quantitative values. And the fuzziness and randomness of concepts are reflected in the certainty grade of cloud drops. Undoubtedly, cloud theory provides a feasible method that could build a connection between qualitative concepts and quantitative numbers.

Studies have shown that the normal cloud model is the most universal cloud model and a large number of random phenomena meet the normal distribution approximately [23]. If there is a number $x \in X$ is a random realization of the concept $Y$ and satisfies $x \sim N\left(E x, E n^{2}\right)$ and $E n^{\prime} \sim N\left(E n, H e^{2}\right)$, the certainty grade of $x$ belonging to concept $Y$ satisfies:

$$
\mu(x)=e^{-\frac{(x-E x)^{2}}{2\left(E n^{\prime}\right)^{2}}}
$$

Then the distribution of $x$ on universal set $X$ is called the normal cloud, and each $x$ is defined as a normal cloud drop.

\section{Cloud Generator, Numerical Characteristics and Algorithm}

Three numerical characteristics are essential to the cloud model: Ex, En, and $H e$ [32, 33], wherein Ex is the expectancy of cloud drop which is the best characterization of a qualitative concept. En is the entropy, depicting the randomness and fuzziness in the concept and also reflecting the granularity scale in the distribution. Hyper-entropy, $H e$, the entropy of $E n$, is used to measure the uncertainty of the membership degree and reflect the degree of dispersion of the cloud droplets. In addition, He describes the relationship between fuzziness and randomness clearly and controls the aggregation of a cloud drop.

By means of the cloud generator, cloud models make it possible to achieve bi-directional transformations between the intension and extension of a qualitative concept. The cloud transformations consist of the normal cloud generator(NCG) and the backward cloud generator(BCG). Moreover, the NCG realizes the transformation from the qualitative concept to the quantitative characteristic; in contrast, the BCG implements the transformation from the quantitative characteristic to the qualitative concept. The cloud transformations make it much easier for simulation of the human cognition process by computer. As many cloud drops as we require can be produced if the three quantitative characteristics are obtained.

The normal cloud generator algorithm can be displayed in algorithm as follows [34]:

a) Calculate expectation En and the standard deviation $\mathrm{He}$;

b) Generate a normally random number $E_{n}{ }^{\prime}$ with expectation $E n$ and standard deviation $H: E n^{\prime} \sim N\left(E n, H e^{2}\right)$;

c) $x_{i}$ is a quantitative value of the qualitative concept, generate a normally random number $x_{i}$ with expectation $E x$ and standard deviation $E_{n}{ }^{\prime}: x_{i} \sim N\left(E x, E n^{2}\right)$; 
d) Calculate certainty degree of quantitative values: $\mu\left(x_{i}\right)=e^{-\frac{\left(x_{i}-E_{x i}\right)^{2}}{2\left(E_{n}\right)^{2}}} ;$

e) Generate a cloud drop with the certainty degree $\mu\left(x_{i}\right)$ and the normally random number $x_{i}$;

f) Repeat steps (a) to (e) until $\mathrm{n}$ required cloud drops are generated.

\section{Risk Assessment of Rockfall Hazards}

The process of risk assessment of rockfall hazards based on the normal cloud model is shown in Fig. 2. Firstly, the geological information is collected, then the assessment index system and levels could be determined. Second, the three characteristics are calculated and cloud drops are built in a graphic way by the normal cloud generator with MATLAB software. Third, a simple dependent function is used to assign the weight. Then, according to the measured date and weight, the certainty grade of each level and the comprehensive certainty grade are obtained by the normal cloud generator, and the risk level of rockfall can finally be determined.

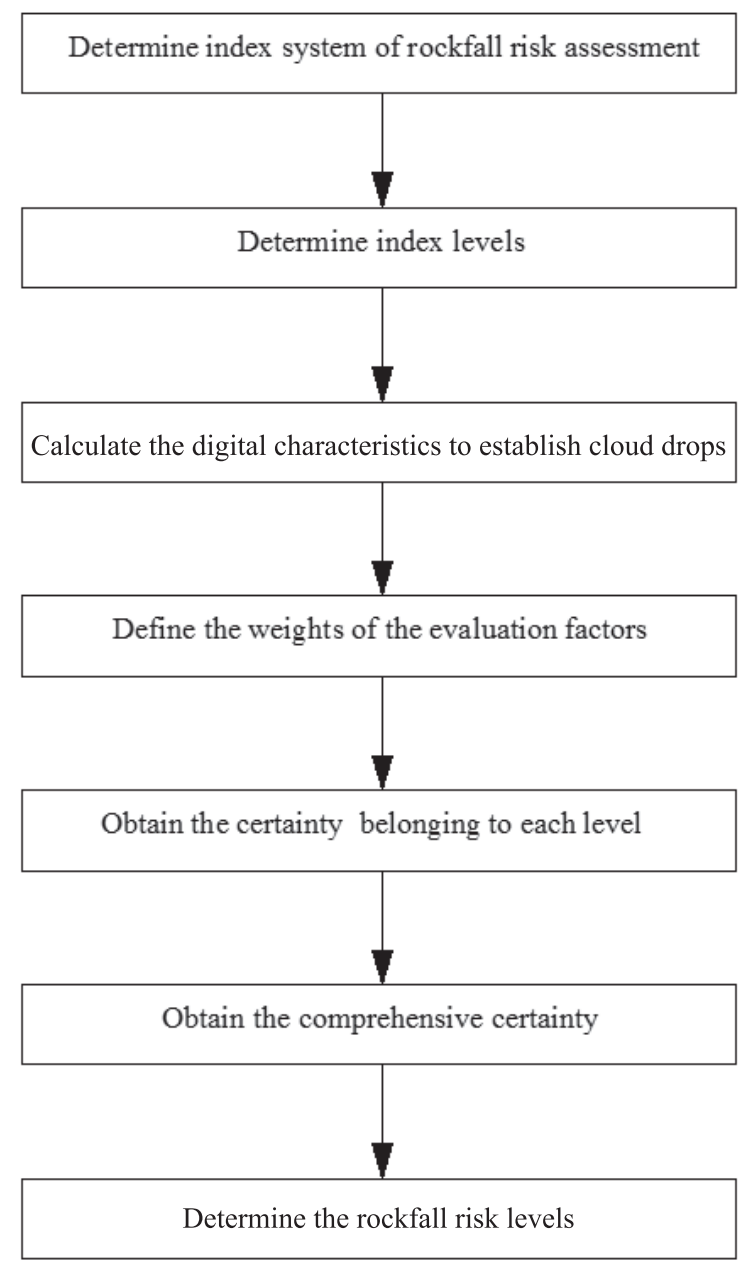

Fig. 2. The process of rockfall risk assessment based on normal cloud model.

\section{Assessment Index System}

Influencing factors of rockfall in a tunnel portal section is extremely complex, consisting of engineering factors and geological factors. Engineering factors are mainly used in dynamic risk assessment. Therefore, only geological factors are considered in this paper as engineering factors are unnecessary for rockfall risk assessment in static evaluation. Geological factors can be divided into geological conditions and hydrogeological conditions. Considering all the geological factors, the main factors include the following 10 indices belonging to three aspects: the characteristics of rockfall, slope condition, and natural environment (Fig. 3).

\section{Assessment Index Levels}

At present, rockfall hazards lack detailed risk assessment in a tunnel. In this paper, according to the results of previous studies [24, 35] and geological conditions of specific project, risk assessment levels of rockfall are divided into four levels: extraordinary stability (I), stability (II), less stability (III), and instability (IV) (Table 1).

Assessment indices should be quantified or corrected after assessment index levels are determined. According to the expert grading method, the qualitative geological indices are quantified by continuous value scale. Specifically, continuous value scale can fully express the opinions of experts compared with discrete value scale. The value of each index was determined by expert scoring (Table 2).

In rockfall shape, rounded and oblate-shaped blocks travel longer distances than others down the slope, followed by square-shaped blocks. Therefore, we adopted the idea that $(0 \sim 25)$ represents oblate or rounded rocks, (26 50) represents bulk rocks, (51 75) represents column rocks, and $(76 \sim 100)$ represents schistose or tapered rocks.

In rockfall shock types, $(0 \sim 30)$ represent the rocks are slide and collapse; (31 50) represent the rocks are slide and roll; $(51 \sim 70)$ represent the rocks collide with each other and bounce; $(71 \sim 100)$ represent the rocks are fall and tumble.

In slope shape, (0 25) represents linear slope and the height is below $0.1 \mathrm{~m},(26 \sim 50)$ represents convex slope and the height is $0.1-0.3 \mathrm{~m},(51 \sim 75)$ represents concave slope and the height is $0.1-0.3 \mathrm{~m}$, and $(76 \sim 100)$ represents slopes with convex top and concave bottom with height above $0.3 \mathrm{~m}$.

In slope lithology, $(0 \sim 25)$ represents very hard rockfall with integrated structure, $(26 \sim 50)$ represents hard rockfall with integrated structure, (51 75) represents fractured rockfall with non-integral structure, and (76 100) represents very fractured rockfall with non-integral structure.

In vegetational cover, (0 60) represents exposed bedrock or excavation surface is hardened; (60 80) represents fewer slope deposits consisting of some rock block, and less vegetation that is mainly grass; (80 90) 


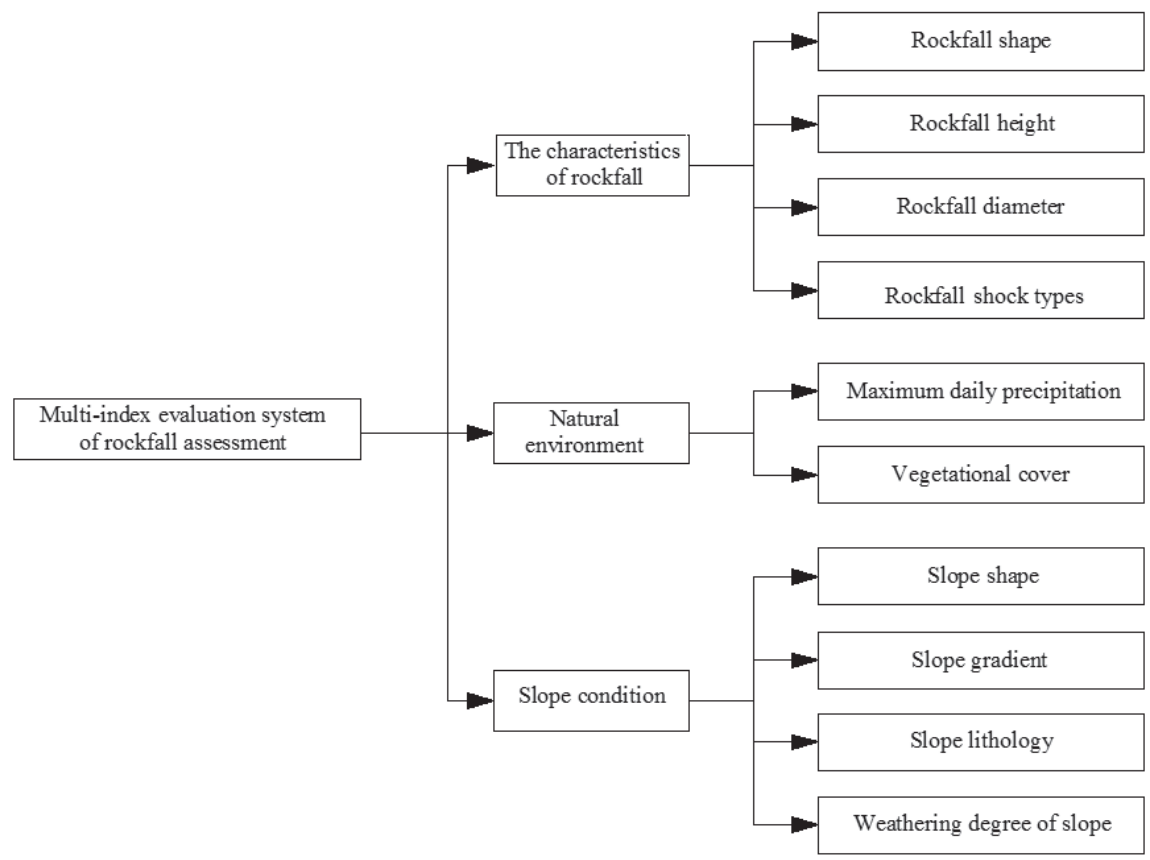

Fig. 3. Multi-index evaluation system of rockfall assessment in a tunnel portal section consisting of geological factors.

represents slope deposit thickness less than $1.0 \mathrm{~m}$, and vegetation consisting of many shrubs and few trees; and $(90 \sim 100)$ represents thick slope deposits, with vegetation consisting of many shrubs and many trees.

In view of the different evaluation units, the normalization method is used to make indices dimensionless, turning specific values of standard levels into account proportion. After normalization, the variation tendency of the primitive value is maintained. The result means that the smaller the value, the lower the risk; it is normalized using Eq.(3). This formula should be calculated as [36]:

$$
c_{i}^{\prime}=\frac{c_{i}-c_{i \min }}{c_{i \max }-c_{i \min }}
$$

Table 1. Rockfall risk assessment level parameter.

\begin{tabular}{|c|c|c|c|c|}
\hline Assessment index & I & II & III & IV \\
\hline Rockfall shape & Oblate & Blocky & Columnar & Schistose or tapered \\
\hline Rockfall shock types & Slide and collapse & Slide and roll & Collide and bounce & Fall and tumble \\
\hline Rockfall height (m) & $0 \sim 20$ & $20 \sim 50$ & $50 \sim 100$ & $>100$ \\
\hline Slope gradient $\left(^{\circ}\right)$ & $0 \sim 35$ & $35 \sim 50$ & $50 \sim 75$ & $>75$ \\
\hline Slope shape & $\begin{array}{l}\text { Linear, slope height } \\
\text { is below } 0.1 \mathrm{~m}\end{array}$ & $\begin{array}{c}\text { Convex, slope height is } \\
0.1-0.3 \mathrm{~m} .\end{array}$ & $\begin{array}{c}\text { Concave, slope height is } \\
0.1-0.3 \mathrm{~m} .\end{array}$ & $\begin{array}{l}\text { Convex top and } \\
\text { concave bottom slope } \\
\text { height is above } 0.3 \mathrm{~m}\end{array}$ \\
\hline Slope lithology & $\begin{array}{l}\text { Very hard rockfall } \\
\text { with integrated } \\
\text { structure }\end{array}$ & $\begin{array}{l}\text { Hard rockfall with } \\
\text { integrated structure }\end{array}$ & $\begin{array}{l}\text { Fractured rockfall with } \\
\text { non-integral structure }\end{array}$ & $\begin{array}{l}\text { Very fractured rockfall } \\
\text { with non-integral } \\
\text { structure }\end{array}$ \\
\hline $\begin{array}{l}\text { Weathering degree of } \\
\text { slope }\end{array}$ & $<5 \%$ & $5 \% \sim 15 \%$ & $15 \% \sim 30 \%$ & $>30 \%$ \\
\hline Rockfall diameter (m) & $<0.3$ & $0.3 \sim 1.0$ & $1.0 \sim 3.0$ & $>3.0$ \\
\hline $\begin{array}{c}\text { Maximum daily } \\
\text { precipitation (mm) }\end{array}$ & $0 \sim 25$ & $25 \sim 75$ & $75 \sim 250$ & $>250$ \\
\hline Vegetation cover & $\begin{array}{l}\text { Exposed bedrock, or } \\
\text { excavation surface is } \\
\text { hardened }\end{array}$ & $\begin{array}{l}\text { Fewer slope deposits } \\
\text { consisting of some rock } \\
\text { block, and less vegetation } \\
\text { that is mainly grass }\end{array}$ & $\begin{array}{l}\text { Slope deposit thickness } \\
\text { is less than } 1.0 \mathrm{~m} \text {, and } \\
\text { vegetation consists of } \\
\text { many shrubs and few trees }\end{array}$ & $\begin{array}{l}\text { Thick slope deposits, } \\
\text { and vegetation } \\
\text { consists of many } \\
\text { shrubs and trees }\end{array}$ \\
\hline
\end{tabular}


Table 2. Normalized standard of rock fall risk assessment level parameter classifications.

\begin{tabular}{|c|c|c|c|c|}
\hline Assessment index & I & II & III & IV \\
\hline Rockfall shape & $0 \sim 0.25$ & $0.25 \sim 0.5$ & $0.5 \sim 0.75$ & $0.75 \sim 1$ \\
\hline Rockfall shock types & $0 \sim 0.3$ & $0.3 \sim 0.5$ & $0.5 \sim 0.75$ & $0.75 \sim 1$ \\
\hline Rockfall height $(\mathrm{m})$ & $0 \sim 0.1$ & $0.1 \sim 0.25$ & $0.25 \sim 0.5$ & $0.5 \sim 1$ \\
\hline Slope gradient $\left(^{\circ}\right)$ & $0 \sim 0.35$ & $0.35 \sim 0.5$ & $0.5 \sim 0.75$ & $0.75 \sim 1$ \\
\hline Slope shape & $0 \sim 0.25$ & $0.25 \sim 0.5$ & $0.5 \sim 0.75$ & $0.75 \sim 1$ \\
\hline Slope lithology & $0 \sim 0.25$ & $0.25 \sim 0.5$ & $0.5 \sim 0.75$ & $0.75 \sim 1$ \\
\hline Weathering degree of slope & $0 \sim 0.1$ & $0.1 \sim 0.3$ & $0.3 \sim 0.6$ & $0.6 \sim 1$ \\
\hline Rockfall Diameter $(\mathrm{m})$ & $0 \sim 0.075$ & $0.075 \sim 0.25$ & $0.25 \sim 0.75$ & $0.75 \sim 1$ \\
\hline Maximum daily precipitation $(\mathrm{mm})$ & $0 \sim 0.067$ & $0.067 \sim 0.25$ & $0.25 \sim 0.83$ & $0.83 \sim 1$ \\
\hline Vegetation cover & $0 \sim 0.6$ & $0.6 \sim 0.8$ & $0.8 \sim 0.9$ & $0.9 \sim 1$ \\
\hline
\end{tabular}

Conversely, the result means that the larger the value, the higher the risk; it is normalized using Eq.(4).

$$
c_{i}^{\prime}=\frac{c_{i \max }-c_{i}}{c_{i \max }-c_{i \min }}
$$

In the formulas, $c_{i}^{\prime}$ is quantitative standard value of assessment index i. $c_{i \text { max }}$ and $c_{i \text { min }}$ are the maximum and minimum quantitative standard value of assessment index $\mathrm{i}$.

\section{Assessment Numerical Characteristics}

Each variable has a boundary: $\left[B_{i \min }, \mathrm{B}_{i \max }\right]$, and numerical characteristics can be expressed as [37]:

$$
\begin{gathered}
E x_{i}=\frac{B_{i \max }+B_{i \min }}{2} \\
E n_{i}= \begin{cases}\frac{E x_{2}-E x_{1}}{3}, & i=1 \\
\frac{E x_{i+1}-E x_{i}}{3}, & i \geq 2\end{cases}
\end{gathered}
$$

$$
H e=k
$$

If a variable has only a single boundary such as $\left[-\infty, B_{i \min }\right]$ or $\left[B_{i \max }+\infty\right]$, its default boundary parameter and $E x_{i}$ can be determined by the value of the upper and lower bounds. Then cloud parameters would be calculated by Eq.(3). He, which is the last digital characteristic of the cloud model, can be set as an appropriate constant $\mathrm{k}$ $(\mathrm{k}<0.5)$, and its value is 0.01 in this paper.

\section{Assessment Index Weight}

In fact, the weight of each index is not absolute, but relative. And the weight should vary with specific data.
Therefore, we introduced a simple dependent function $[38,39]$ to determine the weight of indices in this paper. The simple dependent function is derived from the extension theory; furthermore, the relevancy between geological factors and rockfall risk can be determined quantitatively by dependent function. And the concept of distance in real variable function is extended to the concept of distance as the basis for the transformation between qualitative concept and quantitative characteristics.

Let $c_{i}$ be the $i$ index for the risk of rockfall hazards, $N_{i}$ be the $j$ level of risk assessment, $v_{i}$ be specific data values for each index, and $V_{i j}=\left(a_{i j}, b_{i j}\right)$ be the numerical range of the index $c_{i}$ for level $N_{i}$. Then $r_{i j}$ is the "distance" of the date $v_{i}$ from the range $V_{i j}$. The main calculation steps for simple dependent function are as follows:

$$
r_{i j}= \begin{cases}\frac{2\left(v_{i}-a_{i j}\right)}{b_{i j}-a_{i j}}, & v_{i} \leq \frac{a_{i j}+b_{i j}}{2} \\ \frac{2\left(b_{i j}-v_{i}\right)}{b_{i j}-a_{i j}}, & v_{i} \geq \frac{a_{i j}+b_{i j}}{2}\end{cases}
$$

In the formula, $i=1,2, \ldots, \mathrm{n} ; j=1,2, \ldots, \mathrm{m}$. Then:

$$
r_{i j_{\max }}\left(v_{i}, V_{i j_{\max }}\right)=\max _{j}\left\{r_{i j}\left(v_{i}, V_{i j}\right)\right\}
$$

The larger level that index $c_{i}$ belongs to, the greater the weight it should be given. The weight of index $c_{i}$ for level $N_{i}$ can be expressed as:

$r_{i}=\left\{\begin{array}{l}j_{\max } \times\left(1+r_{i j_{\max }}\left(v_{i}, V_{i j_{\max }}\right)\right), r_{i j_{\max }}\left(v_{i}, V_{i j_{\max }}\right) \geq-0.5 \\ j_{\max } \times 0.5, r_{i j_{\max }}\left(v_{i}, V_{i j_{\max }}\right)<-0.5\end{array}\right.$

In contrast, this formula should be expressed as: 
a)

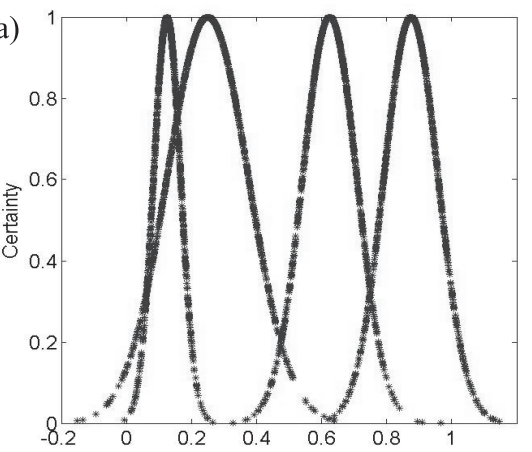

c)

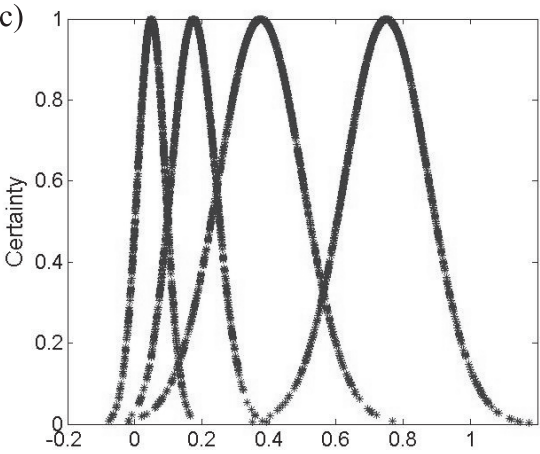

e)

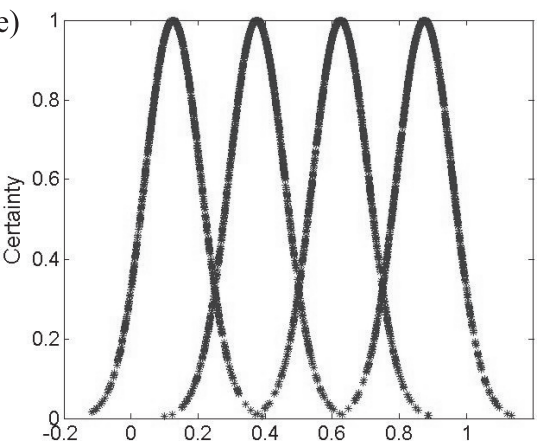

g)

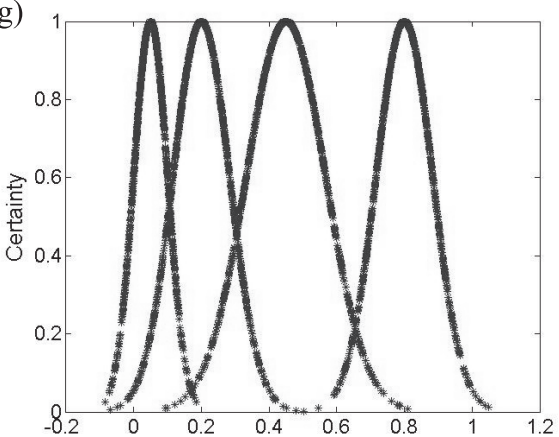

i)

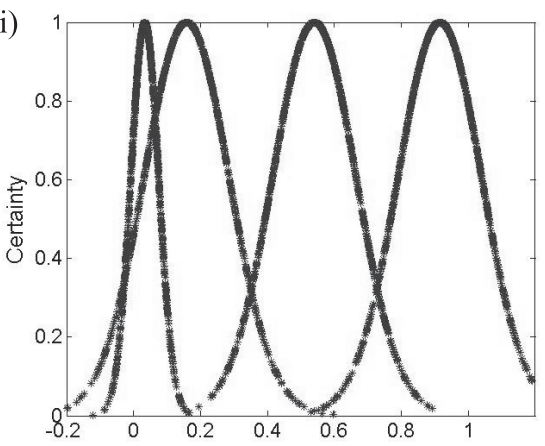

b)

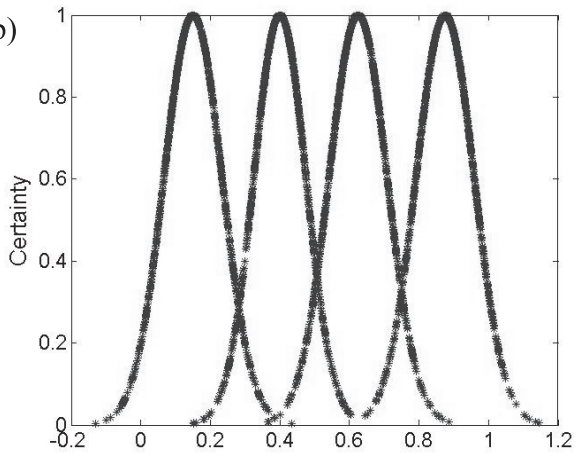

d)

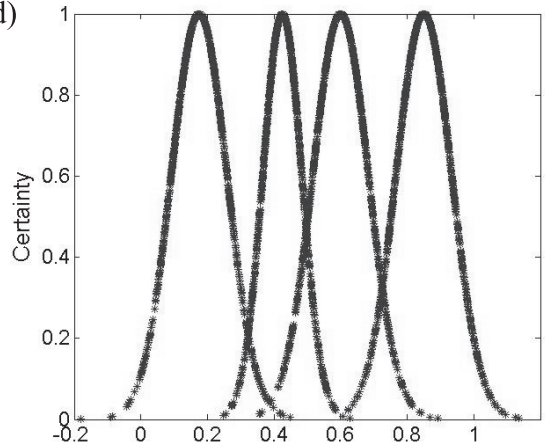

f)

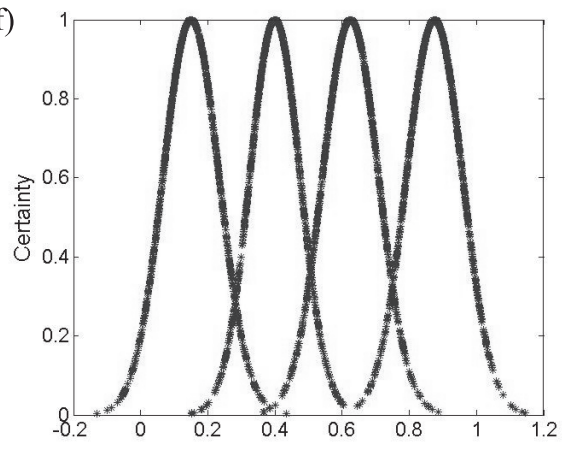

h)

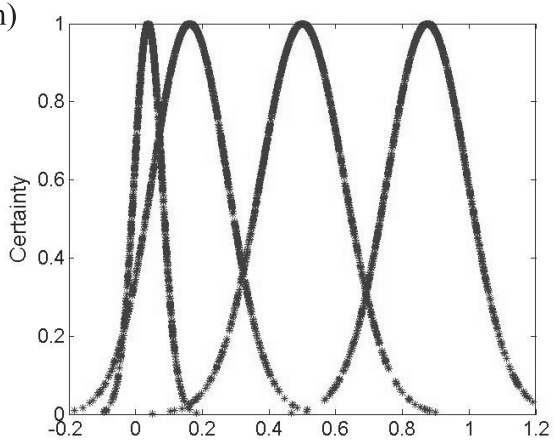

j)

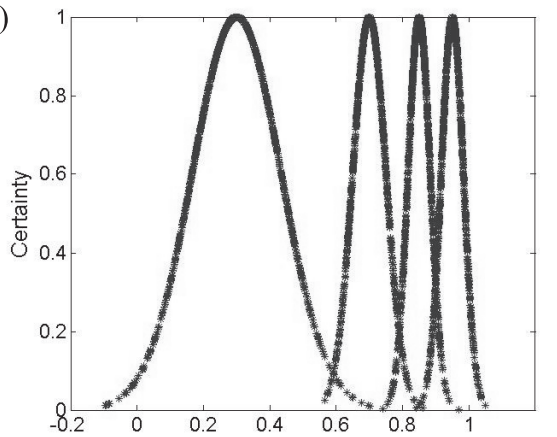

Fig. 4. Cloud for each evaluation factor established by the normal cloud generator. a) Rockfall shape, b) Rockfall shock types, c) Rockfall height, d) Slope gradient, e) Slope shape, f) Slope lithology, g) Weathering degree of slope, h) Rockfall diameter, i) Maximum daily precipitation, j) Vegetation cover. 


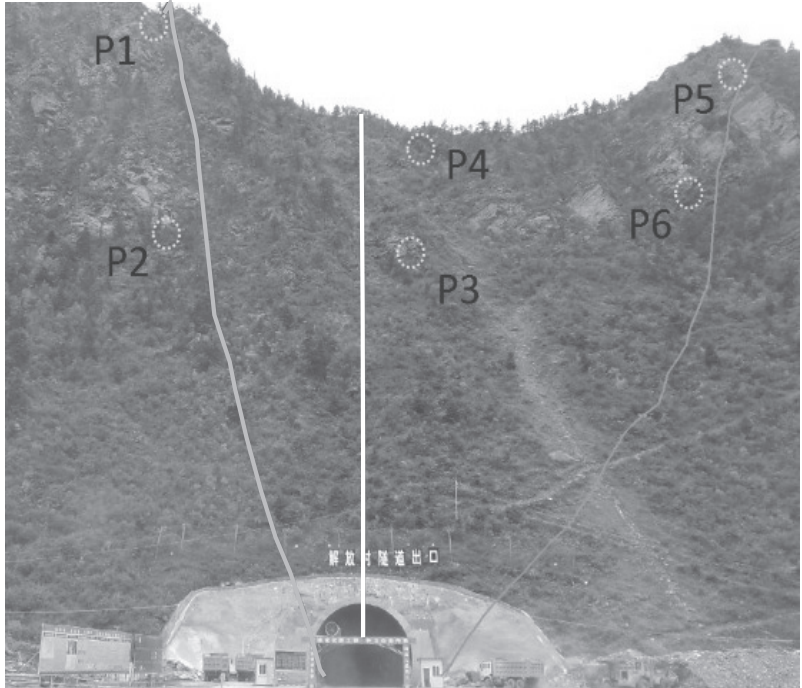

Fig. 5. The main region of dangerous rocks that remain prone to cause disasters above the Jiefangcun Tunnel entrance.

$r_{i}= \begin{cases}\left(m-j_{\max }+1\right) \times\left(1+r_{i j_{\max }}\left(v_{i}, V_{i j_{\max }}\right)\right), & r_{i j_{\max }}\left(v_{i}, V_{i j_{\max }}\right) \geq-0.5 \\ \left(m-j_{\max }+1\right) \times 0.5, & r_{i j_{\max }}\left(v_{i}, V_{i j_{\max }}\right)<-0.5\end{cases}$

The weight of index $c_{i}$ is:

$$
a_{i}=\frac{r_{i}}{\sum_{i=1}^{n} r_{i}}
$$

\section{Generation of Normal Cloud Model}

The normal cloud model of rockfall in a tunnel portal section can be set up using the normal cloud generator (Fig. 4). The certainty grade of each level of rockfall risk assessment in a tunnel portal section is calculated by the normal cloud generator. Then, combining with the simple dependent function, the integrated certainty degree $\mathrm{M}$ can be calculated as follows:

$$
M=\sum_{i=1}^{j} \mu a_{i}
$$

In the formula, $\mu$ is the certainty grade of an assessment level and $a_{i}$ is the weight of index $i$.

\section{Results and Discussion}

We chose the Jiefangcun tunnel portal section as the study area. The main region and index parameter of dangerous rocks above the tunnel entrance is shown in Fig. 5, Table 3, and Table 5.

Based on the cloud model method, the process can be carried out as follows:

1) Based on the normalization method, the rockfall index parameters are normalized by using Eq.(3) or Eq.(4), and the computed values are shown in Tables 4 and 5 .

2) In view of the simple dependent function, the weight of indices of rocks are taken as $0.331,0.475,0.426$, $0.464,0.338,0.509,0.678,0.582,0.306$, and 0.509 , respectively.

$a=\left[\begin{array}{ccccccc} & P_{1} & P_{2} & P_{3} & P_{4} & P_{5} & P_{6} \\ a_{1} & 0.078 & 0.031 & 0.079 & 0.022 & 0.054 & 0.067 \\ a_{2} & 0.104 & 0.062 & 0.105 & 0.060 & 0.054 & 0.090 \\ a_{3} & 0.070 & 0.064 & 0.084 & 0.048 & 0.083 & 0.077 \\ a_{4} & 0.076 & 0.067 & 0.089 & 0.079 & 0.105 & 0.048 \\ a_{5} & 0.023 & 0.058 & 0.042 & 0.068 & 0.066 & 0.081 \\ a_{6} & 0.078 & 0.092 & 0.079 & 0.089 & 0.081 & 0.090 \\ a_{7} & 0.104 & 0.123 & 0.105 & 0.119 & 0.108 & 0.119 \\ a_{8} & 0.054 & 0.108 & 0.032 & 0.140 & 0.108 & 0.140 \\ a_{9} & 0.047 & 0.055 & 0.047 & 0.054 & 0.049 & 0.054 \\ a_{10} & 0.078 & 0.092 & 0.079 & 0.089 & 0.081 & 0.090\end{array}\right]$

$$
\begin{gathered}
K\left(a_{1}\right)=\left[\begin{array}{lllll}
0.331 & 0.475 & 0.426 & 0.464 & 0.338 \\
0.509 & 0.678 & 0.582 & 0.306 & 0.509
\end{array}\right]
\end{gathered}
$$

\begin{tabular}{|c|c|c|c|c|c|c|}
\hline Assessment index & $p_{1}$ & $p_{2}$ & $p_{3}$ & $p_{4}$ & $p_{5}$ & $p_{6}$ \\
\hline Rockfall shape & Cuboid & Flat or cone & Square & Flat or cone & Plate & Cuboid \\
\hline $\begin{array}{l}\text { Rockfall shock } \\
\text { types }\end{array}$ & Bounce, fall & Slide, roll & $\begin{array}{l}\text { Collide with } \\
\text { each other }\end{array}$ & Slide, roll & Slide, roll & $\begin{array}{l}\text { Collide and } \\
\text { bounce }\end{array}$ \\
\hline Rockfall height & $60 \mathrm{~m}$ & $57 \mathrm{~m}$ & $82 \mathrm{~m}$ & $50 \mathrm{~m}$ & $96 \mathrm{~m}$ & $43 \mathrm{~m}$ \\
\hline Slope shape & $\begin{array}{l}\text { Convex top and } \\
\text { concave bottom, slope } \\
\text { height is } 0.35 \mathrm{~m}\end{array}$ & $\begin{array}{c}\text { Convex, slope } \\
\text { height is } 0.2 \\
\mathrm{~m}\end{array}$ & $\begin{array}{l}\text { Concave, } \\
\text { slope height } \\
\text { is } 0.3 \mathrm{~m}\end{array}$ & $\begin{array}{l}\text { Concave, } \\
\text { slope height } \\
\text { is } 0.2 \mathrm{~m}\end{array}$ & $\begin{array}{c}\text { Convex top and } \\
\text { concave bottom, } \\
\text { slope height is } 0.4 \mathrm{~m}\end{array}$ & $\begin{array}{l}\text { Concave, } \\
\text { slope height } \\
\text { is } 0.24 \mathrm{~m} \\
\end{array}$ \\
\hline Slope gradient & $58^{\circ}$ & $48^{\circ}$ & $45^{\circ}$ & $45^{\circ}$ & $55^{\circ}$ & $40^{\circ}$ \\
\hline Rockfall Diameter & 0.3 & 0.5 & 0.1 & 0.6 & 0.5 & 0.6 \\
\hline
\end{tabular}

Table 3. Dangerous rock index parameters above the tunnel entrance. 
Table 4. Normalized results of dangerous rock index parameters above the tunnel entrance.

\begin{tabular}{|c|c|c|c|c|c|c|}
\hline Assessment index & $p_{1}$ & $p_{2}$ & $p_{3}$ & $p_{4}$ & $p_{5}$ & $p_{6}$ \\
\hline Rockfall shape & 0.50 & 0.15 & 0.65 & 0.15 & 0.30 & 0.55 \\
\hline Rockfall shock types & 0.70 & 0.30 & 0.70 & 0.30 & 0.30 & 0.50 \\
\hline Rockfall height & 0.30 & 0.25 & 0.41 & 0.28 & 0.48 & 0.21 \\
\hline Slope shape & 0.75 & 0.46 & 0.68 & 0.46 & 0.80 & 0.60 \\
\hline Slope gradient & 0.64 & 0.53 & 0.50 & 0.50 & 0.61 & 0.44 \\
\hline Rockfall diameter & 0.70 & 0.50 & 0.90 & 0.90 & 0.50 & 0.40 \\
\hline
\end{tabular}

Table 5. Normalized results of index parameter of the tunnel entrance.

\begin{tabular}{|c|c|c|}
\hline Assessment index & Tunnel entrance & $\begin{array}{c}\text { Normalized } \\
\text { value }\end{array}$ \\
\hline Slope lithology & $\begin{array}{c}\text { Crushed rock } \\
\text { with non-integral } \\
\text { structure }\end{array}$ & 0.50 \\
\hline $\begin{array}{c}\text { Weathering degree } \\
\text { of slope }\end{array}$ & Moderate degree & 0.50 \\
\hline $\begin{array}{c}\text { Maximum daily } \\
\text { precipitation }\end{array}$ & $120 \mathrm{~mm}$ & 0.37 \\
\hline Vegetation cover & $\begin{array}{c}\text { Vegetation } \\
\text { consists of some } \\
\text { shrubs and few } \\
\text { trees }\end{array}$ & 0.83 \\
\hline
\end{tabular}

3) Based on the obtained normal cloud model method and the weight of indices, the numerical characteristics and the certainty grades can be discerned by the normal cloud generator by using Eq.(13).

4) The evaluation results of rocks are presented in Table 6.

The results of the proposed cloud model-based method were compared with that of AHP-FUZZY [18, 40] and Artificial Neural Networks (ANN) methods $[19,41-42]$. In the AHP-FUZZY model, the weight was assigned by the Analytic Hierarchy Process method, and the priorities of each index were determined according to experts' opinions. Fuzzy theory was introduced to address the imprecise index system. Then a comprehensive evaluation vector was established by performing the fuzzy operation between the set of fuzzy weights and the fuzzy relationship matrix. On the other hand, in the ANN model an artificial neural network was established with three layers. The input and output layers represent independent variables and dependent variables of the system, respectively. Moreover, the hidden layer is used to perform the transformations. Specifically, the input layer has 10 neurons and the output layer has four neurons in this study. Furthermore, ANN is used for estimating outputs about the levels of assessment by using the inputs of rockfall shape, slope gradient, rockfall diameter and other seven factors. In short, the calculated results of the normal cloud model method, AHP-FUZZY, and ANN are listed in Table 6.

In Table 6, each rock can be generally classified within four status levels from low to high. Considering the overall results of the cloud model method, the levels of rock $p_{1}$, $\operatorname{rock} p_{2}, \operatorname{rock} p_{3}, \operatorname{rock} p_{4}, \operatorname{rock} p_{5}$, and rock $p_{6}$ are IV, III, III, III, IV, and III, respectively. Thus, we can conclude that the cloud model-based approach achieves transformation between qualitative and quantitative analysis. For example, the rockfall height of rock $p_{1}$ was $60 \mathrm{~m}$, which should belong to III grade according to Table 1, and we obtained the results in rockfall height by the normal cloud generator: $\mu_{I}=0, \mu_{I I}=0.0176, \mu_{I I I}=0.0833, \mu_{I V}=$ 0.0002 . Therefore, the results by quantitative analysis are $\mu_{I I I}>\mu_{I I}>\mu_{I V}>\mu_{I}$. Then we can come to the conclusion that rockfall height of rock $p_{1}$ more likely belongs to grade III, likely belongs to grade II, and almost impossibly belongs to grades I and IV, since the conclusion is consistent with the qualitative analysis.

Furthermore, by indicating the degree of certainty belonging to each risk level, the certainty degree provides more detailed information. For example, the level of rock $p_{3}$ is more likely to be III than the level of rock $p_{2}$ and rock $p_{6}$, because the certainty degree of level IV of rock $p_{3}$ $(0.4699)$ is higher than that of rock $p_{2}(0.4048)$ and rock $p_{6}(0.4355)$.

In this paper, the collected data are enough for the assessment. If the available information for the risk assessment is very limited in similar projects, probabilistic models, interval models, and imprecise probabilities should be considered [43-47]. Specifically, when all parameters are collected as random variables, probabilistic models are proposed; for cases in which all parameters are collected as interval variables, interval models have behaved with some favourable features; when parameters are described by random variables and interval parameters, respectively, imprecise probabilities with components of fuzzy set theory can be quite helpful. But the results are usually conservative as a result of the consideration of extreme events.

Generally speaking, results of five rocks $\left(p_{1}, p_{2}, p_{3}\right.$, $\left.p_{5}, p_{6}\right)$ from the various methods are exactly the same, except for rock $p_{4}$, because the methods for calculating the weight are different. Therefore, the data in Table 6 show high consistency of the results between the proposed 
Table 6. Risk evaluation results of rockfall in tunnel portal section.

\begin{tabular}{|c|c|c|c|c|c|c|c|}
\hline \multirow{2}{*}{ Rock } & \multicolumn{4}{|c|}{ The integrated certainty degree } & \multirow{2}{*}{$\begin{array}{l}\text { The normal cloud } \\
\text { model method }\end{array}$} & \multirow{2}{*}{$\begin{array}{l}\text { AHP-FUZZY } \\
\text { method }\end{array}$} & \multirow{2}{*}{$\begin{array}{c}\text { The ANN } \\
\text { method }\end{array}$} \\
\hline & M (I) & M (II) & M (III) & M (IV) & & & \\
\hline$p_{1}$ & 0.0001 & 0.0782 & 0.4715 & 0.4864 & IV & IV & IV \\
\hline$p_{2}$ & 0.0735 & 0.2417 & 0.4048 & 0.0789 & III & III & III \\
\hline$p_{3}$ & 0.0002 & 0.0937 & 0.4699 & 0.1402 & III & III & III \\
\hline$p_{4}$ & 0.0742 & 0.2444 & 0.3802 & 0.1417 & III & III & IV \\
\hline$p_{5}$ & 0.0184 & 0.1556 & 0.4345 & 0.4817 & IV & IV & IV \\
\hline$p_{6}$ & 0.0016 & 0.2737 & 0.4355 & 0.0065 & III & III & III \\
\hline
\end{tabular}

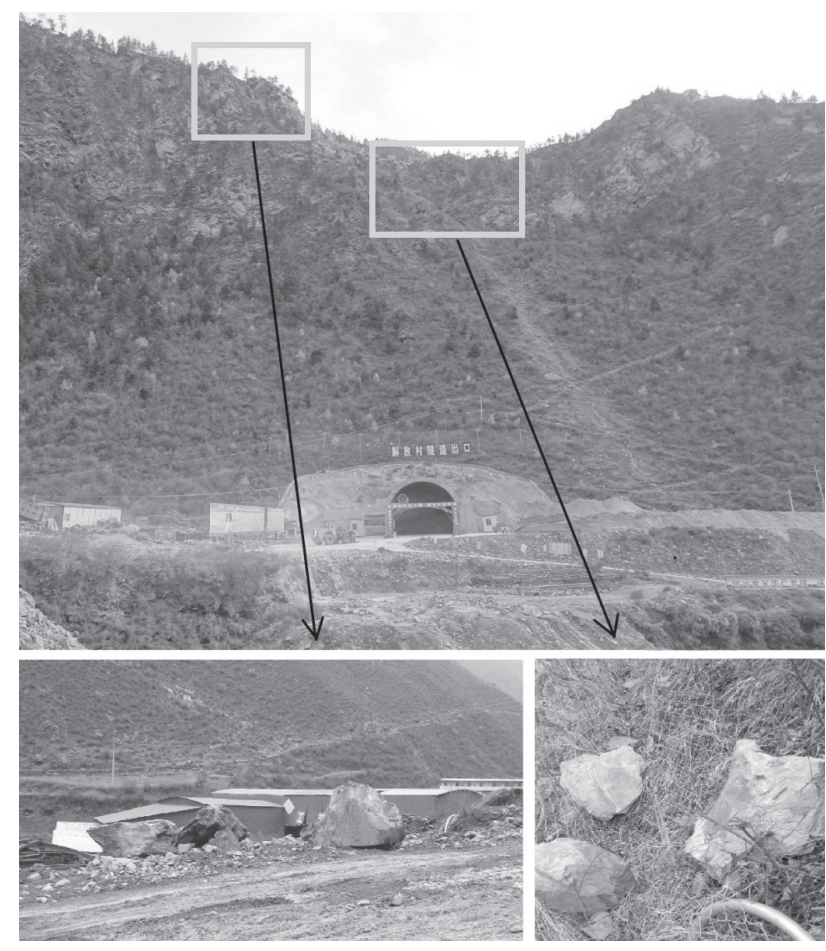

Fig. 6. Verification by practical situation.

normal cloud model and other two methods. Considering that the calculation of the proposed method is quicker and simpler, the normal cloud model method is better than AHP-FUZZY and artificial neural network methods.

During the construction of Jiefangcun Tunnel, rockfall occurred in the portal section. Rock $p_{1}$ and rock $p_{5}$ fall along the escarpment due to prolonged rain seriously interrupted traffic at the tunnel entrance. Moreover, some gravel around rock $p_{4}$ moved down the slope (Fig. 6). Fortunately, it did not cause any casualties. Therefore, the evaluation results obtained from the proposed method are generally in good agreement with the practical situation in Jiefangcun Tunnel.

\section{Conclusions}

Rockfall is a typical geological disaster in mountainous regions that is especially serious in southwestern China.
Based on normal cloud theory, in this paper a multi-index evaluation system is presented to systematically evaluate the risk of the rockfall hazards for tunnels in Sichuan Province.

Moreover, according to previous research and specific geological conditions, the potential dangers in the tunnel are classified into four ranks, and some geological factors such as rockfall shape and slope gradient are considered. In order to fully express the opinions of experts, the qualitative indices are quantified by continuous value scale, and the value of each index is determined by expert scoring. And then the weight of indices is rationally assigned by a simple dependent function. Finally, based on the three numerical characteristics calculated by the cloud generator algorithm with MATLAB, cloud drops were generated and the integrated certainty grades were determined.

The cloud model method was tested in rockfall cases in Jiefangcun Tunnel and the results by the present method are in good agreement with the practical situation. Moreover, the result is compared with those of AHPFUZZY and artificial neural networks methods as well. In view of the fact that some potential rockfall is still perched on the slope above the portal section of Jiefangcun Tunnel, some proper rockfall protection designs should be applied to mitigate rockfall disasters, such as constructing protective wire nets and building rock fences.

Applying our findings to Jiefangcun Tunnel showed that the proposed method is feasible both in theory and practice. Thus, the cloud model-based method provides a practical guide on safe tunnel construction for similar projects. In this paper, we introduced the one-dimensional normal cloud model into rockfall risk assessment. Considering the successful application of the present model, two-dimensional and multi-dimensional cloud modeling strategies are worth exploring in rockfall risk assessment or other applications.

\section{Acknowledgements}

Much of the work presented in this paper was supported by the State Key Development Program for Basic Research of China (grant No. 2013CB036001) and the State Key Program of National Natural Science 
of China (grant No. 51139004). National Natural Science Foundations of China (grant numbers 51379112 and 51422904), and Shandong Provincial Natural Science Foundation (grant number JQ201513). The authors would like to express appreciation to the reviewers for their valuable comments and suggestions that helped improve the quality of our paper.

\section{References}

1. YI Z. On the climatic uncertainty to the environment extremes: a Singapore case and statistical approach. Polish Journal of Environmental Studies, 24 (3), 1413, 2015.

2. YOUSSEF A.M., PRADHAN B., AL-KATHERY M., BATHRELLOS G.D., SKILODIMOUS H.D. Assessment of rockfall hazard at Al-Noor Mountain, Makkah city (Saudi Arabia) using spatio-temporal remote sensing data and field investigation. Journal of African Earth Sciences, 101, 309, 2015.

3. SCHÖPA A., BAEWERT H., COOK K., MORCHE D. Recent rock fall activity in the Wetterstein Mountains revealed by a time series of terrestrial laser scans. Mathematical Programming, 119 (1), 169, 2009.

4. CHOI Y., YOON S.Y., Park H.D. Tunneling Analyst: A 3D GIS extension for rock mass classification and fault zone analysis in tunneling. Computers \& Geosciences, 35 (6), 1322, 2009.

5. GORTMAKER S L., MUST A., SOBOL A M., PETERSON K., COLDITZ G.A. Assessment of Rockfall Hazard along the Road Cut Slopes of State Highway-72, Maharashtra, India. Geomaterials, 3 (1), 15, 2013.

6. CALCETTI F., PRISCO C.D. An Uncoupled Approach for the Design of Rockfall Protection Tunnels. Structural Engineering International, 19 (3), 342, 2009.

7. RUNQIU H. Geo-engineering lessons learned from the 2008 Wenchuan earthquake in Sichuan and their significance to reconstruction. Journal of Mountain Science, 8, 176, 2011.

8. MENG X.L. Earthquake Disaster Characteristics of Tunnel 109 on Baoji-Chengdu Railway and Measures for Urgent Repair and Treatment. Journal of Railway Engineering Society, 6, 91, 2009.

9. FRATTINI P., CROSTA G., CARRARA A., AGLIARDI F. Assessment of rockfall susceptibility by integrating statistical and physically-based approaches. Geomorphology, 94 (3-4), 419, 2008.

10. MICHOUD C., DERRON M.H., HORTON P., JABOYEDOFF M., BAILLIFARD F.J., LOYE A., NICOLET P., PEDRAZZINI A., QUEYREL A. Rockfall hazard and risk assessments along roads at a regional scale: example in Swiss Alps. Natural Hazards \& Earth System Sciences, 12(3), 615, 2012.

11. OKURA Y., KITAHARA H., SAMMORI T., KAWANAMI A. The effects of rockfall volume on runout distance. Engineering Geology, 58 (2) 109, 2000.

12. LABIOUSE V. Fragmental rockfall paths: Comparison of simulations on Alpine sites and experimental investigation of boulder impacts. Ninth International Symposium on Landslides, 457, 2004.

13. VOLKWEINA., KLETTE J. Semi-Automatic Determination of Rockfall Trajectories. Sensors, 14 (10), 18187, 2013.

14. VOLKWEIN A., KRUMMENACHER B., GERBER W., LARDON J., GEES F. Repeated controlled rockfall trajectory testing. EGU General Assembly Conference. EGU General Assembly Conference Abstracts, 17, 2015.
15. LI Z.H., HUANG H.W., XUE Y.D., YIN J. Risk assessment of rockfall hazards on highways. Georisk Assessment \& Management of Risk for Engineered Systems \& Geohazards, 3 (3), 147, 2009.

16. YE S., TANG H., CHEN H., ZHU H. Stability evaluation of rockfall based on AHP-Fuzzy method. Seventh International Conference on Fuzzy Systems and Knowledge Discovery, 3, 1369, 2010.

17. GAO Y., DUAN Y.S., LIU J.W. Genetic strategy rough set of particle swarm optimization neural network application in collapse rockfall hazard risk assessment. Journal of Highway and Transportation Research and Development, 10 (1), 106, 2010. [In Chinese].

18. FENG L., ZHU X., SUN X. Assessing coastal reclamation suitability based on a fuzzy-AHP comprehensive evaluation framework: A case study of Lianyungang, China. Marine Pollution Bulletin, 89 (1-2), 102, 2014.

19. BAYRAM A., KANKAL M. Artificial Neural Network Modeling of Dissolved Oxygen Concentrations in a Turkish Watershed. Polish Journal of Environmental Studies, 24 (4), 1507, 2015.

20. YE S., TANG H., CHEN H., ZHU H. Stability evaluation of rockfall based on AHP-Fuzzy method. Seventh International Conference on Fuzzy Systems and Knowledge Discovery, 3, 1369, 2010.

21. RUSSELL C.P., SANTI P.M., HUMPHREY J.D. Modification and Statistical Analysis of the Colorado Rockfall Hazard Rating System. Engineering Geology, 104 (1), 55, 2008.

22. WANG X.L., FRATTINI P., CROSTA G. B., ZHANG L.Q., AGLIARDI F., LARI F., YANG Z.F. Uncertainty assessment in quantitative rockfall risk assessment. Landslides, 11 (4), $711,2014$.

23. GENIŞ M., SAKIZ U., AYDINER B Ç. A stability assessment of the rockfall problem around the Gökgöl Tunnel (Zonguldak, Turkey). Bulletin of Engineering Geology \& the Environment, 1, 2016

24. YE S.Q., CHEN H.K. The evaluation method for the hazard grading of the rockfall at the slope segment of the tunnel entrance. China Railway Science, 5, 59, 2010 [In Chinese].

25. LI D., MENG H., Shi X. Membership clouds generators and membership cloud. Journal of Computer Research \& Development, 32 (6), 15, 1995 [In Chinese].

26. LI D., Du Y. Artificial intelligence with uncertainty. International Conference on Computer and Information Technology, 15 (11), 2, 2004.

27. WANG G., XU C., LI D. Generic normal cloud model. Information Sciences, 280(280), 1, 2014.

28. SUN X.X., CAI C., YANG J., SHEN, X.B. Route Assessment for Unmanned Aerial Vehicle Based on Cloud Model. Mathematical Problems in Engineering, 1, 2014.

29. ÉLISABETH RANISAVLJEVIĆ., DEVIN F., LAFFLY D., NIR Y.L. A dynamic and generic cloud computing model for glaciological image processing. International Journal of Applied Earth Observation \& Geoinformation, 27 (4), 109, 2014.

30. LIU J., WEN G., XIE Y.M. Layout optimization of continuum structures considering the probabilistic and fuzzy directional uncertainty of applied loads based on the cloud model. Structural \& Multidisciplinary Optimization, 53 (1), $81,2016$.

31. ZHANG X., LIU, Z., JIA C. A novel marine traffic safety assessment based on cloud models. International Workshop on Education Technology \& Computer Science. IEEE Computer Society, 59, 2010. 
32. DU X.Y., YI Q.J., HUANG K.D., LIANG D.N. Transformation between qualitative variables and quantity based on cloud models and its application. Systems Engineering \& Electronics System. 30 (4), 772, 2008.

33. KAVOUSI-FARD A., NIKNAM T., FOTUHI-FIRUZABAD M. A novel stochastic framework based on cloud theory and h-modified bat algorithm to solve the distribution feeder reconfiguration. IEEE Transactions on Smart Grid, 99, 1, 2015.

34. LI Z., LIU Y. Single rule reasoning mapping for the two dimensional normal cloud model. Caai Transactions on Intelligent Systems. 5 (5), 464, 2010.

35. PIERSON L.A., VICKLE R.V. Rockfall Hazard Rating System: Participant's Manual, Implementation, USA, 12, 1993.

36. AN Y.1., PENG L.M., WU B. Comprehensive extension assessment on tunnel collapse risk. Journal of Central South University, 2, 514, 2011.

37. LI L., LIU L., YANG C., LI Z. The Comprehensive Evaluation of Smart Distribution Grid Based on Cloud Model. Energy Procedia, 17 (Part A), 96, 2012.

38. WEN C. The extension set and non-compatible problems. Advances in applied mathematics and mechanics in China, 2, 138, 1990.

39. JIA C., XIAO S., LIU N. Application of extentics theory to evaluation of tunnel rock quality. Chinese Journal of Rock Mechanics \& Engineering, 22 (5), 751, 2003.

40. XIANG Z.Q. Preventive technology of unstable rock and rockfall hazard at tunnel entrance in high and steep slope. Southwest Jiaotong Univerisity, 2013 [In Chinese].
41. VALIRON G., COLLINGWOOD E.F. Applying Artificial Neural Networks for the Estimation of Chlorophyll-a Concentrations along the Istanbul Coast. Polish Journal of Environmental Studies, 23 (4), 1281, 2014.

42. FARIS H., ALKASASSBEH M., RODAN A. Artificial Neural Networks for Surface Ozone Prediction: Models and Analysis. Polish Journal of Environmental Studies, 23 (2), 341, 2014.

43. BEER M., YI Z., QUEK S.T., PHOON KK. Reliability analysis with scarce information: Comparing alternative approaches in a geotechnical engineering context. Structural Safety, 41 (3), 1, 2013.

44. ZHANG H., DAI H., BEER M., WANG W. Structural reliability analysis on the basis of small samples: An interval quasi-Monte Carlo method. Mechanical Systems \& Signal Processing, 37 (s1-2), 137, 2013.

45. DEGRAUWE D., LOMBAERT G., DE ROECK G. Improving interval analysis in finite element calculations by means of affine arithmetic. Computers \& Structures, 88 (3), 247, 2010.

46. HANSS M., TURRIN S. A fuzzy-based approach to comprehensive modeling and analysis of systems with epistemic uncertainties. Structural Safety, 32 (6), 433, 2010.

47. MÖLLER B., BEER M. Engineering computation under uncertainty-capabilities of non-traditional models, special issue on uncertainties in structural analysis. Computers \& Structures, 86 (10), 1024-41, 2008. 